\title{
Determination of Nine Hydroxylated Polybrominated Diphenyl Ethers and Forty Polybrominated Diphenyl Ethers in Atmospheric Fine Particles by Precolumn Derivatization-GC-MS/GC
}

\author{
Pengyan Liu ${ }^{1,2^{*}}$, Yunfeng $\mathrm{Xu}^{1}$, Xiaobing Wang ${ }^{1}$, Zhansheng $\mathrm{Li}^{1}$ and $\mathrm{Gu} \mathrm{Jing}^{1}$ \\ ${ }^{1}$ College of Chemistry and Environmental Science, Baoding 071000, PR China \\ ${ }^{2}$ Key Laboratory of Analytical Science and Technology of Hebei Province, Baoding 071000, PR China
}

\begin{abstract}
Environmental context: Hydroxylated polybrominated diphenyl ethers (OH-PBDEs) and polybrominated diphenyl ethers (PBDEs) in $\mathrm{PM}_{2.5}$ can be toxic to humans and ecosystems, because they will show endocrine disrupting activity. It is thus important to understand the contamination level of PBDEs and OH-PBDEs in $\mathrm{PM}_{2.5}$ In this paper, a method has been applied to the analysis and separation of trace PBDEs and OH-PBDEs in $\mathrm{PM}_{2.5}$, in order to understand the pollution levels, migration and transformation of PBDEs/OH-PBDEs in $\mathrm{PM}_{2.5}$.

In this study, we demonstrate a method for simultaneously analyzing $9 \mathrm{OH}-\mathrm{PBDEs}$ and 40 PBDEs existed in $\mathrm{PM}_{2.5}$. Quantitative analysis was conducted by using gas chromatography (GC) and gas chromatography-mass spectrometry (GC-MS) combined with a precolumn derivatization. To achieve accurate detection, the extraction solvents and cleanup condition were optimized. The working curves were obtained via dissolving standards in blank matrix extracts. The linear range of 9 OH-PBDEs was from $15 \mathrm{pg} \mathrm{m}^{-3}$ to $3875 \mathrm{pg} \mathrm{m}^{-3}$, and limits of detection and quantification ranged from $4.95 \mathrm{pg} \mathrm{m}^{-3}$ to $24.33 \mathrm{pg} \mathrm{m}^{-3}$ and $16.48 \mathrm{pg} \mathrm{m}^{-3}$ to $81.09 \mathrm{pg} \mathrm{m}^{-3}$, respectively. The linear range of 40 PBDEs was from $1.25 \mathrm{pg} \mathrm{m}^{-3}$ to $5000 \mathrm{pg} \mathrm{m}^{-3}$, and limits of detection and quantification ranged from $0.37 \mathrm{pg} \mathrm{m}^{-3}$ to $38.19 \mathrm{pg} \mathrm{m}^{-3}$ and 1.25 $\mathrm{pg} \mathrm{m}^{-3}$ to $127.29 \mathrm{pg} \mathrm{m}^{-3}$, respectively. The results showed that the recoveries were in the range of $72.1 \%-104.7 \%$ and the relative standard deviations were less than $13.6 \%$. This method was suitable for simultaneous analysis of PBDEs and $\mathrm{OH}-\mathrm{PBDEs}$ in $\mathrm{PM}_{2.5}$ with the advantages of high sensitivity, time saving and easy operation. The applicability of the method has been successfully validated on atmospheric samples collected in Baoding, China. Six PBDEs and five $\mathrm{OH}-\mathrm{PBDEs}$ were detected in all the samples. Among the detected PBDEs and OH-PBDEs, detection rate of BDE-47, BDE-99, BDE-100 and BDE-209 were relatively higher than that of others. The results indicated that the concentration of BDE-209 might be affected by the concentration of $\mathrm{PM}_{2.5}$.
\end{abstract}

Keywords: Gas chromatography; Mass spectrometry; Gas chromatography; Hydroxylated polybrominated diphenyl ethers; Polybrominated diphenyl ethers; Deteminaion; $\mathrm{PM}_{2.5}$

\section{Introduction}

Polybrominated diphenyl ethers (PBDEs) are one class of brominated flame retardants (BFRs). Hydroxy polybrominated diphenyl ethers (OH-PBDEs) as metabolites of PBDEs in the environment, are potentially more toxic than their parent PBDEs [1]. At present, PBDEs and OH-PBDEs are ubiquitous in all environmental media (air, soil, sediment, indoor air), organisms (fish, birds, mammals) and in human body (breast milk, blood, tissue and bile) [2,3], etc. The PBDEs in the environment can be transported and transformed over long distances through the atmosphere, causing harm to the ecological environment and human health [4]. Thus the analysis of these organic pollutants in the atmosphere has major significance for studying $\mathrm{PM}_{2.5}$ source apportionment and transformation of organic pollutants.

The issue of air pollution has raised public concern in China. $\mathrm{PM}_{2.5}$ is one of the prime pollutant parameters that affect urban air quality. $\mathrm{PM}_{2.5}$ are harmful to human health not only because they can enrich most organic pollutants [5] and heavy metal elements, but also because they are small enough to penetrate deeply into the lungs. The chemical composition of $\mathrm{PM}_{2.5}$ in the atmosphere is very complex. Besides heavy metals, alkanes, polycyclic aromatic hydrocarbons (PAHs), esters, heterocyclic compounds [6-8], and persistent organic pollutants such as PBDEs and $\mathrm{OH}-\mathrm{PBDEs}$ are all present in $\mathrm{PM}_{2.5}$. Current research about the noxious pollutants in $\mathrm{PM}_{2.5}$ are extensively focused on heavy metals, PAHs and on phthalic acid ester [REF]. However, the studies about pollution level and source of PBDEs in $\mathrm{PM}_{2.5}$ are rather limited.
Furthermore, there is little information available in literature about the pollution of $\mathrm{OH}-\mathrm{PBDEs}$ in $\mathrm{PM}_{2.5}$. The ecotoxicological studies found that $\mathrm{OH}-\mathrm{PBDEs}$ are stronger endocrine disruptors than their precursor PBDEs. For example, OH-PBDEs will disrupt thyroid hormone action and possess pseudo/anti estrogenic activities even in a low concentration range of micromolar per liter [9-11]. Therefore, it is considerably important to understand the contamination level of PBDEs and $\mathrm{OH}-$ PBDEs in $\mathrm{PM}_{2.5}$. However, determination of PBDEs and OH-PBDEs in $\mathrm{PM}_{2.5}$ is difficult due to the following reasons: 1 ) the concentration of PBDEs and OH-PBDEs in $\mathrm{PM}_{25}$ is very low; 2) the complex composition of $\mathrm{PM}_{2.5}$ induces matrix interference; 3 ) Considering the weak polarity of the phenol hydroxyl group in OH-PBDEs, simultaneously extracting and separating PBDEs and OH-PBDEs from $\mathrm{PM}_{2.5}$ are not trivial. Currently the main pretreatment methods for analyzing different polarity fractions require several steps, including extraction, separation and clean-up. Numerous techniques have been developed for extracting analytes, such as accelerated solvent extraction (ASE) [12], Soxhlet

*Corresponding authors: Pengyan Liu, College of Chemistry and Environmental Science, No. 180 Wusi East Road, Baoding 071000, PR China, Tel: 9526146462; E-mail: hbupyliu@163.com

Received October 10, 2017; Accepted October 16, 2017; Published October 20, 2017

Citation: Liu P, Xu Y, Wang X, Li Z, Jing G (2017) Determination of Nine Hydroxylated Polybrominated Diphenyl Ethers and Forty Polybrominated Diphenyl Ethers in Atmospheric Fine Particles by Precolumn Derivatization-GC-MS/GC. J Environ Anal Toxicol 7: 518. doi: 10.4172/2161-0525.1000518

Copyright: $\odot 2017$ Liu P, et al. This is an open-access article distributed under the terms of the Creative Commons Attribution License, which permits unrestricted use, distribution, and reproduction in any medium, provided the original author and source are credited. 
Citation: Liu P, Xu Y, Wang X, Li Z, Jing G (2017) Determination of Nine Hydroxylated Polybrominated Diphenyl Ethers and Forty Polybrominated Diphenyl Ethers in Atmospheric Fine Particles by Precolumn Derivatization-GC-MS/GC. J Environ Anal Toxicol 7: 518. doi: 10.4172/21610525.1000518

Page 2 of 9

extraction (SE) [13], and ultrasound assisted extraction (UAE) [14]. Among them, SE was widely used in the extraction of air filters. The methods for separation of the neutral (PBDEs) and phenol $(\mathrm{OH}-$ PBDEs) analytes involves partitioning with potassium hydroxide were widely used [15-21]. Another common technique to separate different polarity components is gel-permeation chromatography. However, this method is laborious, sophisticated and consumes a large amount of organic solvent $[22,23]$. Regardless of separation technique, analyzing $\mathrm{PM}_{2.5}$ samples requires complicated clean-up procedure to reduce matrix interference. Florisil [24] silicon gel [25] and alumina [26] are often used in clean-up procedure. Among them, silicon gel can be used in clean-up procedure for the separation of analytes from interfering compounds of a different chemical polarity.

This paper presents an approach for simultaneous analyzing PBDEs and $\mathrm{OH}-\mathrm{PBDEs}$ with an improved sample pretreatment. Different polar fractions were separated via controlling $\mathrm{pH}$ of liquid-liquid extraction and then purified by acidic silica columns. PBDEs were analyzed by GCECD. OH-PBDEs were analyzed by GC-MS after derivatization with N,O-bis (trimethylsilyl) trifluoroacetamide (BSTFA) [27]. BSTFA was used as derivatization reagent in OH-PBDEs determination. Compared with diazomethane and dimethyl sulfate, it has the advantages of low toxicity, minimal interference, and easy operation $[16,28]$. This method for determining 9 OH-PBDEs and 40 PBDEs in atmospheric fine particles was highly efficient and sensitive, requiring small amount of samples and reagents. Meanwhile, it can eliminate the interference induced by impurities in the atmosphere. This method will provide a practical reference to understand the pollution levels, migration and transformation of PBDEs/OH-PBDEs in atmospheric fine particles.

\section{Experimental}

\section{Chemicals and reagents}

Standard solutions, 2'-hydroxy-4-monobromodiphenyl ether (2'-OH-BDE-3), 3'-hydroxy-2,4-dibromodiphenyl ether (3'-OHBDE-7), 2'-hydroxy-2,4,4'-tribromodiphenyl ether (2'-OH-BDE-28), 3' -hydroxy-2,4,4' -tribromodiphenyl ether (3'-OH-BDE-28), 4' -hydroxy-2,2', 4-tribromodiphenyl ether (4'-OH-BDE-17), 2' -hydroxy-2,3',4,5' -tetrabromodiphenyl ether (2' -OH-BDE-68), 5-hydroxy-2,2', 4,4' -tetrabromodiphenyl ether (5-OH-BDE-47), 6-hydroxy-2,2', 4,4' -tetrabromodiphenyl ether (6-OH-BDE-47), 5' -hydroxy-2,2', 4,4', 5-pentabromodiphenyl ether (5'-OH-BDE-99), BDE209 and the standard solution of 39 PBDE congeners (BDE-1, 2, 3, 7, 8, $10,11,12,13,15,17,25,28,30,32,33,35,37,47,49,66,71,75,77,85$, $99,100,116,118,119,126,138,153,154,155,166,181,183,190)$ were purchased from Accustandard (New Haven, CT, USA). Acetonitrile, isooctane, dichloromethane, hexane, methyl tert-butyl ether and N,Obis (trimethylsilyl) trifluoroacetamide (BSTFA) (98\%) were obtained from J\&K Scientific Ltd (Beijing). Isopropyl alcohol was purchased from Tedia (USA). Acetone and toluene were obtained from JT Baker (Phillipsburg, NJ, USA). Alcohol was purchased from Fisher Scientific. All of the above solvents were HPLC grade. Hydrochloric acid $(\mathrm{HCl})$, concentrated sulfuric acid $\left(\mathrm{H}_{2} \mathrm{SO}_{4}\right)$, sodium hydroxide $(\mathrm{NaOH})$, sodium chloride $(\mathrm{NaCl})$, anhydrous sodium sulfate $\left(\mathrm{Na}_{2} \mathrm{SO}_{4}\right)$ and silica (100200 mesh) were analytical grade. Glass fiber filters [effective diameter $(90 \pm 1) \mathrm{mm}$ ] applied to collect $\mathrm{PM}_{2.5}$ were obtained from Whatman (Loughborough, UK). Glass chromatography columns $(30 \mathrm{~cm} \times 1.0 \mathrm{~cm}$ i.d) applied to clean up were purchased from Beijing Xingyun Kenuo trading company (Beijing, China).

\section{Equipment}

7890A Gas chromatography with 5975C mass spectrometry, 7890B Gas chromatography (Agilent Technologies, Ltd.), Termovap sample concentrator BF-2000M (Beijing eight Century Technology Co. Ltd.), Rotary evaporator RV 10 control (IKA Works Guangzhou), Vortex shaker WH-861 (Taicang Hualida laboratory equipment company), Electric thermostatic drying oven DHG-9053A (Shanghai Feiyue Experimental Instrument Co. Ltd.), P8846X high volume mass flow controlled system for $\mathrm{PM}_{10} / \mathrm{PM}_{25}$ sampler with the flow rate of $1 \mathrm{~m}^{3} \mathrm{~min}$ ${ }^{1}$ (Tisch Environmental Inc, OH, USA). Analytical balance AB 135-S (METTLER TOLEDO Co. Ltd.).

\section{Sampling}

$\mathrm{PM}_{2.5}$ samples were collected on the top of a university building at a height of approximately $10 \mathrm{~m}\left(38^{\circ} 52^{\prime} 17.99^{\prime \prime} \mathrm{N}, 115^{\circ} 30^{\prime} 35.06^{\prime \prime} \mathrm{E}\right)$ from September 2016 to January 2017. Active sampling using glass fiber filters is routinely employed for sampling $\mathrm{PM}_{2.5}$. The sampling duration was $8 \mathrm{~h}$ either during daytime from 10:00 to 18:00 or at night from 22:00 to 06:00 using a P8846X high volume mass flow controlled system for $\mathrm{PM}_{10} / \mathrm{PM}_{2.5}$ sampler with the flow rate of $1 \mathrm{~m}^{3} \mathrm{~min}^{-1}$. Before collecting $\mathrm{PM}_{2.5}$, the glass fiber filters were pre-baked at $500^{\circ} \mathrm{C}$ for $4 \mathrm{~h}$ and stored in the dryer at room temperature and relative humidity (40\%-60\%) for at least $24 \mathrm{~h}$. The filters were weighed in the electronic balance $(0.01$ mg precision) with gravimetric methods before and after sampling, respectively. All collected samples were wrapped by aluminum foil and stored at $\leq-18^{\circ} \mathrm{C}$ in the freezer prior to analysis.

\section{Sample preparation}

Standard mixture solutions and spiking solutions series preparation: According to the response value, the standard solutions of nine $\mathrm{OH}-\mathrm{PBDEs}$ were diluted with acetonitrile to the following concentrations: $12 \mu \mathrm{g} \mathrm{mL} \mathrm{m}^{-1}$ 2'-OH-BDE-3, $12 \mu \mathrm{g} \mathrm{mL} \mathrm{mL}^{-1}$ 3'-OH-BDE-7, $10 \mu \mathrm{g} \mathrm{mL}{ }^{-1} 2^{\prime}-\mathrm{OH}-\mathrm{BDE}-28,8 \mu \mathrm{g} \mathrm{mL} \mathrm{m}^{-1} 3^{\prime}-\mathrm{OH}-\mathrm{BDE}-28,12.5 \mu \mathrm{g} \mathrm{mL}{ }^{-1}$ 4'-OH-BDE-17, $11 \mu \mathrm{g} \mathrm{mL}{ }^{-1}$ 5-OH-BDE-47, $10 \mu \mathrm{g} \mathrm{mL}-1$ 6-OH-BDE-47, $10 \mu \mathrm{g} \mathrm{mL}{ }^{-1} 2^{\prime}-\mathrm{OH}-\mathrm{BDE}-68$, and $10 \mu \mathrm{g} \mathrm{mL}^{-1} 5^{\prime}-\mathrm{OH}-\mathrm{BDE}-99$. Then they are mixed together in a ratio of 2:5:10:12:10:10:10:10:31 (v/v). The final concentration was $0.24,0.6,1.0,0.96,1.25,1.1,1.0,1.0,3.1 \mu \mathrm{g} \mathrm{mL}^{-1}$, respectively. $2 \mathrm{mg}$ of decabromodiphenyl ether (BDE-209) was put into $50 \mathrm{~mL}$ hexane. Then the solution is placed in an ultrasonic chamber for 20 mins for complete dissolution. $1 \mathrm{~mL} 40 \mu \mathrm{g} \mathrm{mL} \mathrm{m}^{-1} \mathrm{BDE}-209$ solution was diluted 20 times with hexane to obtain the standard solution of $2 \mu \mathrm{g}$ $\mathrm{mL}^{-1} \mathrm{BDE}-209$. Similarly, we obtained the standard solution of BDE-47, BDE-99, BDE-100 with the same procedure. Then all standard solutions were stored at $\leq-18^{\circ} \mathrm{C}$.

Silica gel preparation: Activated silica gel: $20 \mathrm{~g}$ of silica gel (100$200 \mathrm{mesh}$ ) was pre-washed with $50 \mathrm{~mL}$ methanol to remove high polar impurities, and then with $50 \mathrm{ml}$ hexane/dichloromethane (DCM) (1:1, $\mathrm{v} / \mathrm{v}$, the following was the same) to get rid of weak polar and nonpolar impurities. Cleaned silica gel was dried and activated at $135^{\circ} \mathrm{C}$ for $4 \mathrm{~h}$. Acid silica gel $\left(\mathrm{H}_{2} \mathrm{SO}_{4}, 30 \%\right)$ was prepared by adding $8.6 \mathrm{~g}$ of sulfuric acid into $20 \mathrm{~g}$ of activated silica. Anhydrous sodium sulfate was baked at $660^{\circ} \mathrm{C}$ for $6 \mathrm{~h}$ and cooled to $150^{\circ} \mathrm{C}$. All of them were reserved in the dryer before use.

Extraction procedures: Air filter was extracted by Soxhlet extractor for $12 \mathrm{~h}$ with $200 \mathrm{~mL}$ of hexane/DCM. The extract was concentrated by rotary evaporation to $5 \mathrm{~mL}$, and then adjusted to acidity with $1 \mathrm{~mL}$ of $6 \mathrm{~mol} \mathrm{~L}^{-1} \mathrm{HCl}$. After that, $5 \mathrm{~mL}$ of isopropyl alcohol and $10 \mathrm{~mL}$ of methyl tert-butyl ether (MTBE)/hexane mixture $(1: 1, \mathrm{v} / \mathrm{v})$ were added into the extracted sample. The extract was washed three times with a total of $30 \mathrm{~mL}(10+10+10 \mathrm{~mL})$ of $3 \% \mathrm{NaCl}$ solution and the organic 
Citation: Liu P, Xu Y, Wang X, Li Z, Jing G (2017) Determination of Nine Hydroxylated Polybrominated Diphenyl Ethers and Forty Polybrominated Diphenyl Ethers in Atmospheric Fine Particles by Precolumn Derivatization-GC-MS/GC. J Environ Anal Toxicol 7: 518. doi: 10.4172/21610525.1000518

Page 3 of 9

layer was transferred to a separatory funnel. Then, $15 \mathrm{~mL}$ of $1 \mathrm{~mol}$ $\mathrm{L}^{-1} \mathrm{NaOH} /$ alcohol $(1: 1, \mathrm{v} / \mathrm{v})$ was added into the separatory funnel to separate the neutral fractions and the weak acid fractions with hydroxyl component. PBDEs was contained in organic phase (I) and OH-PBDEs was contained in water phase. The $\mathrm{pH}$ of water layers containing $\mathrm{OH}$ PBDEs was adjusted to acidity with $0.1 \mathrm{~mL}$ of $\mathrm{H}_{2} \mathrm{SO}_{4}(50 \%)$ Then the water phase were extracted three times with a total of $20 \mathrm{~mL}$ of methyl tert-butyl ether (MTBE)/hexane mixture $(1: 1, \mathrm{v} / \mathrm{v}, 10+5+5 \mathrm{~mL})$ and then organic fractions (II) containing OH-PBDEs were collected.

Clean up and derivation: The volumes of two organic fractions ((I), (II)) were both concentrated to $1 \mathrm{~mL}$ before being subjected to silica gel column. The concentrated solutions were cleaned-up using two acid-base silica gel columns $(30 \mathrm{~cm}$ i.d) Both of the acid-base silica gel columns were packed from the bottom to the top with absorbent cotton, $0.5 \mathrm{~g}$ of activated silica gel, $2 \mathrm{~g}$ of acid silica geland $3 \mathrm{~cm}$ of anhydrous sodium sulfate. The two columns were pre-washed with 45 $\mathrm{mL}$ of hexane/DCM. Then organic phase (I) containing PBDEs was added into a column and eluted with $40 \mathrm{~mL}$ of hexane/DCM. Organic phase (II) containing OH-PBDEs was added into the other column and eluted with $35 \mathrm{~mL}$ of hexane/DCM. Both of eluates were collected and evaporated to almost dryness under a stream of nitrogen. Then $100 \mu \mathrm{L}$ of BSTFA was added to elution fraction (II) containing OH-PBDEs and vortex mixed for $1 \mathrm{~min}$. Elution fraction (II) was incubated at $90^{\circ} \mathrm{C}$ for $30 \mathrm{~min}$, then cooled at room temperature. Ultimately, fraction (I) containing PBDEs and fraction (II) containing OH-PBDEs were nitrogen evaporated to almost dryness and reconstituted in $100 \mu \mathrm{L}$ of hexane prior to instrumentally analyzed by GC-ECD and GC-MS, respectively (Figure 1).

\section{Instrumental analysis}

GC conditions: The quantification of PBDEs was performed with GC with DB-5HT column $(15 \mathrm{~m} \times 0.25 \mathrm{~mm}$ i.d. $\times 0.10 \mu \mathrm{m})$. High purity nitrogen (purity $\geq 99.999 \%$ ) was used as carrier gas at a constant flow rate of $1.0 \mathrm{~mL} \mathrm{~min}^{-1}$. Sample injection was set at $1 \mu \mathrm{L}$ in chromatographic method. The injection temperature and detector temperature were set at $300^{\circ} \mathrm{C}$ and $340^{\circ} \mathrm{C}$, respectively. The programmed GC oven temperature was initiated at $45^{\circ} \mathrm{C}$, held $1.0 \mathrm{~min}$, ramp $25^{\circ} \mathrm{C} \mathrm{min} \mathrm{m}^{-1}$ to $150^{\circ} \mathrm{C}$, held 1.0 min, ramp $4^{\circ} \mathrm{C} \mathrm{min}^{-1}$ to $320^{\circ} \mathrm{C}$ and held 3.0 mins. Chromatogram of the forty PBDEs were shown in Figure 2.

\section{GC-MS conditions}

Chromatographic separation: The quantification of OH-PBDEs

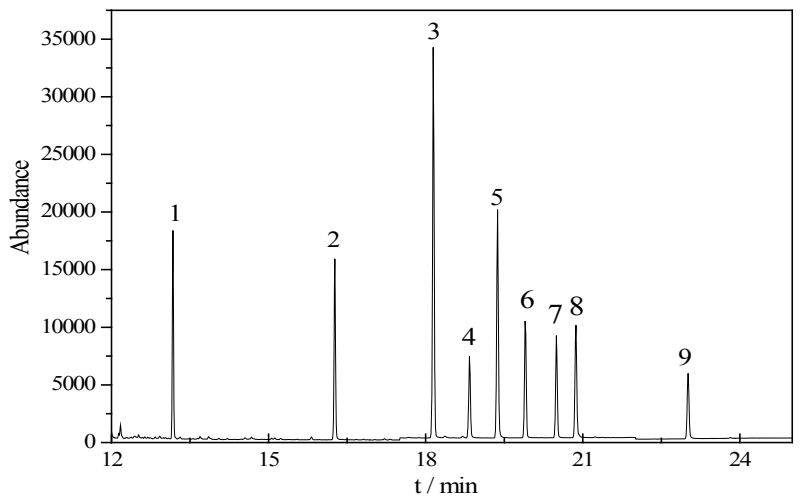

Figure 1: Selected ion chromatogram of the nine OH-PBDEs. 1. 2'-OHBDE-3; 2. 3'-OH-BDE-7; 3. 2'-OH-BDE-28; 4. 3'-OH-BDE-28; 5. 4'-OHBDE-17; 6. 6-OH-BDE-47; 7. 2'-OH-BDE-68; 8. 5-OH-BDE-47; 9. 5'-OHBDE-99. was performed with a GC-MS. Compounds separation was achieved using a DB-35MS column $(30 \mathrm{~m} \times 0.32 \mathrm{~mm}$ i.d. $\times 0.25 \mu \mathrm{m})$ with high purity helium (purity $\geq 99.999 \%$ ) as the carrier gas at a constant flow of $1.0 \mathrm{~mL} \mathrm{~min}^{-1}$. Sample injection was set at $1 \mu \mathrm{L}$ and the injection temperature was set at $250^{\circ} \mathrm{C}$. The programmed GC oven temperature was initially $45^{\circ} \mathrm{C}$, held for $1 \mathrm{~min}$, increased to $200^{\circ} \mathrm{C}$ at $15^{\circ} \mathrm{C} \mathrm{min}{ }^{-1}$, then to $300^{\circ} \mathrm{C}$ at $8^{\circ} \mathrm{C} \mathrm{min}^{-1}$, and held for 10 mins.

Mass parameters: Electron ionization (EI) was used in mass spectrometer with an electron energy of $70 \mathrm{eV}$. The temperatures of ion source and the transfer line were set at $230^{\circ} \mathrm{C}$ and $280^{\circ} \mathrm{C}$, respectively. The mass spectrometer was operated in SIM mode and SCAN mode, respectively. Selected ion chromatogram of the nine OH-PBDEs was shown in Figure 1. Retention times of 9 OH-PBDEs and 40 PBDEs were listed in Tables 1 and 2.

\section{Results and Discussion}

\section{Conditions optimization}

Optimization of cleanup conditions: Two acid-base silica gel columns were rinsed with $45 \mathrm{~mL}$ of hexane/DCM. After that $1 \mathrm{~mL}$ of 9 OH-PBDEs mixture and $1 \mathrm{~mL}$ of 4 PBDEs mixture were poured over the columns, respectively. Hexane, dichloromethane and hexane/ DCM were used as elution solvents. The eluent was collected every $5 \mathrm{~mL}$ and was determined to investigate three solvents' elution.

Optimization of elution solvent: If hexane was used as the elution solvent, only BDE-209 could be eluted completely. If dichloromethane was used as the elution solvent, the low-BDEs could be eluted completely. While hexane/DCM as eluent solvent, low-BDEs, highBDEs and hydroxylated polybrominated diphenyl ethers could be all flown out. Therefore, the mixed hexane/DCM was considered to be the most suitable elution solvent.

Optimization of elution volume: When hexane/DCM was used as the elution solvent, BDE-47/99/100 began to flow out at $0-5 \mathrm{~mL}$ and reached the maximum value at $5-10 \mathrm{~mL} .35 \mathrm{~mL}$ of solvent can elute BDE-47/99/100 entirely. BDE-209 reached the maximum value at 5-10 $\mathrm{mL}$ and it was eluted entirely at an elution volume of $40 \mathrm{~mL}$; Therefore, $40 \mathrm{~mL}$ of hexane/DCM was the optimum elution volume to elute polybrominated diphenyl ethers.

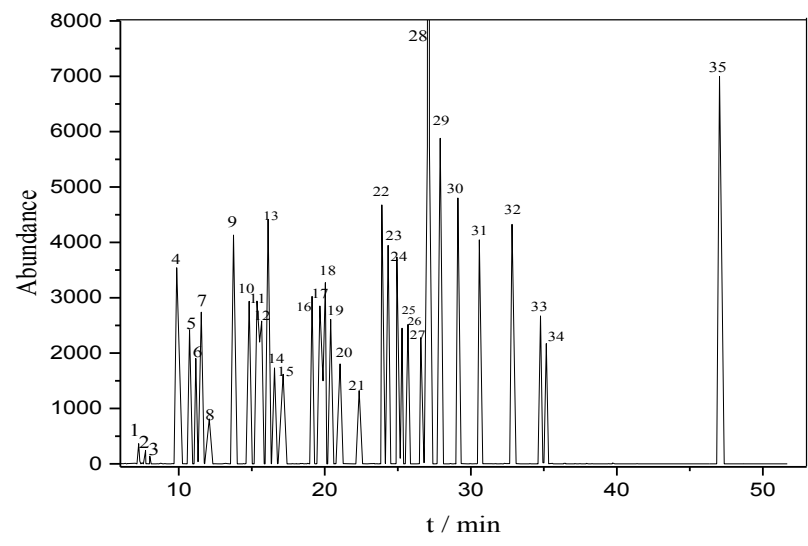

Figure 2: Chromatogram of the forty PBDEs. 1. BDE-1; 2 . BDE-2; 3 , BDE-3 4. BDE-10; 5. BDE-7; 6. BDE-11/8; 7. BDE-12/13; 8. BDE-15; 9. BDE-30; 10 BDE-32; 11. BDE-17; 12. BDE-25; 13. BDE-33/28; 14.BDE-35; 15.BDE-37; 16. BDE-75; 17. BDE-49; 18. BDE-71.19. BDE-47; 20. BDE-66; 21. BDE-77; 22. BDE-100; 23. BDE-119; 24. BDE-99; 25. BDE-116; 26. BDE-118; 27. BDE-85; 28. BDE-126/155; 29. BDE-154; 30. BDE-153; 31. BDE-138/166; 32. BDE-183; 33. BDE-181; 34. BDE-190; 35. BDE-209. 
Citation: Liu P, Xu Y, Wang X, Li Z, Jing G (2017) Determination of Nine Hydroxylated Polybrominated Diphenyl Ethers and Forty Polybrominated Diphenyl Ethers in Atmospheric Fine Particles by Precolumn Derivatization-GC-MS/GC. J Environ Anal Toxicol 7: 518. doi: 10.4172/21610525.1000518

Page 4 of 9

\begin{tabular}{|c|c|c|c|c|c|c|}
\hline No. & Date & Pollution degree & Weather condition & $\begin{array}{l}\text { Before sampling } \\
\text { (g) }\end{array}$ & $\begin{array}{l}\text { After sampling } \\
\text { (g) }\end{array}$ & $\begin{array}{c}\mathrm{PM}_{2.5} \text { concentration } \\
\left(\mu \mathrm{g} \mathrm{m}^{-3}\right)\end{array}$ \\
\hline 1 & 2016.09 .23 & Unhealthy & $\begin{array}{c}17-27^{\circ} \mathrm{C} \\
\text { Sunny-Cloudy } \\
\text { Winds S at } 1-2 \text { grade }\end{array}$ & 2.84985 & 2.92226 & 150.85 \\
\hline 2 & $2016.09 .23-24$ & Very Unhealthy & $\begin{array}{c}17-27^{\circ} \mathrm{C} \\
\text { Sunny-Cloudy } \\
\text { Winds } \mathrm{S} \text { at } 1-2 \text { grade }\end{array}$ & 2.85687 & 2.95291 & 200.08 \\
\hline 3 & 2016.10 .09 & Moderate & $\begin{array}{c}7-19^{\circ} \mathrm{C} \\
\text { Sunny-Cloudy } \\
\text { Winds } S \text { at } 1-2 \text { grade }\end{array}$ & 2.84197 & 2.88048 & 80.23 \\
\hline 4 & 2016.10.11-12 & $\begin{array}{l}\text { Unhealthy for } \\
\text { Sensitive Groups }\end{array}$ & $\begin{array}{c}9-22^{\circ} \mathrm{C} \\
\text { Sunny } \\
\text { Winds } \mathrm{N} \text { at } 1-2 \text { grade }\end{array}$ & 2.85953 & 2.90739 & 99.71 \\
\hline 5 & 2016.10 .13 & Very Unhealthy & $\begin{array}{c}11-23^{\circ} \mathrm{C} \text { Sunny } \\
\text { Winds } \mathrm{S} \text { at } 1-2 \text { grade }\end{array}$ & 2.8539 & 2.99769 & 299.56 \\
\hline 6 & 2016.11 .03 & Hazardous & $\begin{array}{c}4-17^{\circ} \mathrm{C} \text { Sunny } \\
\text { Winds } S \text { at } 1-2 \text { grade }\end{array}$ & 2.84406 & 2.88739 & 90.27 \\
\hline 7 & 2016.12 .05 & Good & $\begin{array}{c}-7-8^{\circ} \mathrm{C} \text { Sunny } \\
\text { Winds WN 3-4 grade }\end{array}$ & 2.81252 & 2.82936 & 35.08 \\
\hline 8 & 2016.12 .19 & Hazardous & $\begin{array}{c}-5-5^{\circ} \mathrm{C} \text { Hazy } \\
\text { Winds } S \text { at } 1-2 \text { grade }\end{array}$ & 2.83884 & 3.08326 & 509.21 \\
\hline 9 & 2016.12 .23 & Moderate & $\begin{array}{c}-6-4^{\circ} \mathrm{C} \text { Sunny } \\
\text { Winds } \mathrm{N} \text { at } 1-2 \text { grade }\end{array}$ & 2.85998 & 2.89188 & 66.46 \\
\hline 10 & 2016.12 .28 & Unhealthy & $\begin{array}{l}-10-3^{\circ} \mathrm{C} \text { Cloudy-Sunny } \\
\text { Winds WN } 1-2 \text { grade }\end{array}$ & 2.83508 & 2.84318 & 16.875 \\
\hline 11 & 2017.01 .03 & Hazardous & $\begin{array}{c}-4-5^{\circ} \mathrm{C} \text { Hazy } \\
\text { Winds } S \text { at } 1-2 \text { grade }\end{array}$ & 2.86693 & 3.13337 & 555.08 \\
\hline 12 & $2017.01 .03-04$ & Very Unhealthy & $\begin{array}{c}-4-5^{\circ} \mathrm{C} \text { Hazy } \\
\text { Winds } S \text { at } 1-2 \text { grade }\end{array}$ & 2.8583 & 2.9897 & 273.75 \\
\hline 13 & 3017.01 .04 & Hazardous & $\begin{array}{l}-3-2^{\circ} \mathrm{C} \text { Hazy-Foggy } \\
\text { Winds EN } 1-2 \text { grade }\end{array}$ & 2.84725 & 2.99875 & 315.63 \\
\hline 14 & 2017.01.04-05 & Hazardous & $\begin{array}{l}-3-2^{\circ} \mathrm{C} \text { Hazy-Foggy } \\
\text { Winds EN } 1-2 \text { grade }\end{array}$ & 2.86268 & 3.05032 & 807.58 \\
\hline 15 & 2017.01 .05 & Very Unhealthy & $\begin{array}{c}-3-2^{\circ} \mathrm{C} \text { Hazy } \\
\text { Winds EN 1-2 grade }\end{array}$ & 2.85528 & 2.96285 & 224.10 \\
\hline 16 & $\begin{array}{l}2017.01 .05 \\
\quad-06\end{array}$ & Very Unhealthy & $\begin{array}{c}-3-2^{\circ} \mathrm{C} \text { Hazy } \\
\text { Winds EN } 1-2 \text { grade }\end{array}$ & 2.86845 & 2.99295 & 259.38 \\
\hline
\end{tabular}

Table 1: Records of weather conditions and mass concentration of $\mathrm{PM}_{2.5}$ during sampling

\begin{tabular}{|c|c|c|c|c|c|}
\hline Name & Retention time (min) & Name & Retention time (min) & Name & Retention time (min) \\
\hline 2'-OH-BDE-3 & 13.602 & BDE12/13 & 11.436 & BDE-100 & 24.143 \\
\hline 3'-OH-BDE-7 & 16.779 & BDE-15 & 11.842 & BDE-119 & 24.486 \\
\hline 2'-OH-BDE-28 & 18.7 & BDE-30 & 13.746 & BDE-99 & 25.167 \\
\hline 3'-OH-BDE-28 & 19.404 & BDE-32 & 15.028 & BDE-116 & 25.409 \\
\hline 4'-OH-BDE-17 & 19.929 & BDE-17 & 15.488 & BDE-118 & 25.971 \\
\hline 6-OH-BDE-47 & 20.473 & BDE-25 & 15.576 & BDE-85 & 26.875 \\
\hline 2'-OH-BDE-68 & 21.068 & BDE-28/33 & 16.117 & BDE-126/155 & 27.168 \\
\hline 5-OH-BDE-47 & 21.445 & BDE-35 & 16.55 & BDE-154 & 27.908 \\
\hline 5'-OH-BDE-99 & 23.604 & BDE-37 & 17.04 & BDE-153 & 29.273 \\
\hline $\mathrm{BDE}-1$ & 7.254 & BDE-75 & 19.559 & BDE-138/166 & 31.016 \\
\hline BDE-2 & 7.404 & BDE-49 & 19.975 & BDE-183 & 33.096 \\
\hline BDE-3 & 7.571 & BDE-71 & 20.097 & BDE-181 & 35.024 \\
\hline BDE-10 & 9.858 & BDE-47 & 20.715 & BDE-190 & 35.304 \\
\hline BDE-7 & 10.74 & BDE-66 & 21.362 & BDE-209 & 46.632 \\
\hline BDE-11/8 & 11.164 & BDE-77 & 22.386 & & \\
\hline
\end{tabular}

Table 2: Retention times of the nine OH-PBDEs and the forty PBDEs.

Among of 9 OH-PBDEs, 4'-OH-BDE-17 began to flow out at $0-5$ $\mathrm{mL}$. while other OH-PBDEs were not detected at 0-5 mL. Except for 2'-OH-BDE-3 and 2'-OH-BDE-28, the others were eluted entirely at an elution volume of $30 \mathrm{~mL}$. 2'-OH-BDE-3 and 2'-OH-BDE-28 were eluted entirely at an elution volume of $35 \mathrm{~mL}$. The elution amount of 9 $\mathrm{OH}-\mathrm{PBDEs}$ reached the maximum value at $5-10 \mathrm{~mL}$ and eluted entirely at an elution volume of $35 \mathrm{~mL}$. Therefore, $35 \mathrm{~mL}$ of hexane/DCM was used to elute hydroxylated polybrominated diphenyl ethers. This results were shown in Figure 3.

\section{Selection of extraction solvent}

A certain amount of standard mixture was added to glass fiber membrane, then $200 \mathrm{~mL}$ of different solvents (toluene, acetone, hexane, dichloromethane and hexane/DCM) were tested for extraction 
Citation: Liu P, Xu Y, Wang X, Li Z, Jing G (2017) Determination of Nine Hydroxylated Polybrominated Diphenyl Ethers and Forty Polybrominated Diphenyl Ethers in Atmospheric Fine Particles by Precolumn Derivatization-GC-MS/GC. J Environ Anal Toxicol 7: 518. doi: 10.4172/21610525.1000518

Page 5 of 9

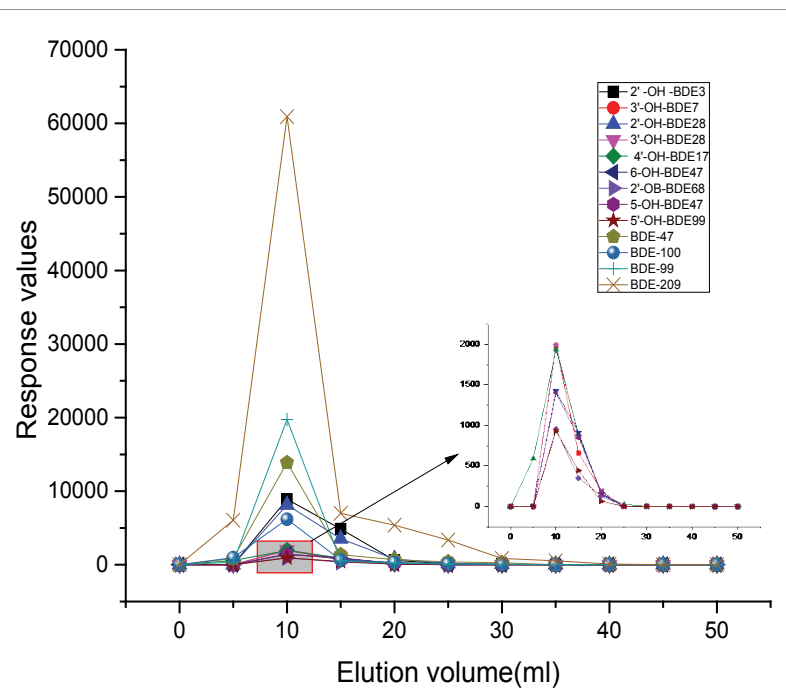

Figure 3: The flow curves of nine OH-PBDEs and BDE-47/99/100/209.

efficiency of the targets, respectively. The comparison of extraction efficiency was in the following sequence: toluene $\approx$ hexane/DCM> acetone $>$ hexane $>$ dichloromethane. The experimental results were shown in Figure 4. It could be seen from Figure 4, both of toluene and hexane/DCM could achieved satisfactory extraction effects. Extraction efficiency of toluene was slightly higher than hexane/DCM, whereas the blank value of solution extracted by toluene was higher than by hexane/DCM. The nitrogen blowing of toluene solution spent longer time than that of hexane/DCM. Therefore, hexane/DCM was the optimum extraction solvent.

\section{Performance of the method}

Linear equations, correlation coefficients $\left(\mathbf{r}^{2}\right)$, limits of detection (LOD) and limits of quantification (LOQ): 5, 10, 20, 50 and $100 \mu \mathrm{L}$ of $9 \mathrm{OH}-\mathrm{PBDEs}$ standard mixture were added to blank membrane, then we could obtain OH-PBDEs series concentration of $62.5,125$, $250,625,1250 \mathrm{pg} \mathrm{m}^{-3}$, respectively. Similarly, 5, 20, 50, 100 and $200 \mu \mathrm{L}$ of 39 PBDEs standard mixture were added to blank membrane, and obtained the concentration of $1.25,5,12.5,25$ and $50 \mathrm{pg} \mathrm{m}^{-3}$ PBDEs, respectively. We could obtain BDE-209 series concentration of 125 , $500,1250,2500$ and $5000 \mathrm{pg} \mathrm{m}^{-3}$ by adding 5, 20, 50, 100 and $200 \mu \mathrm{L}$ of BDE-209 standard solution to blank membrane, respectively. The quality assurance and quality control procedures included procedural blank and parallel duplicate samples. The measurement values were the average value of three parallel determinations. Based on measurement values of peak area and concentration, linear equations were generated. The linear range of $9 \mathrm{OH}-\mathrm{PBDEs}$ was from $15 \mathrm{pg} \mathrm{m}^{-3}$ to $3875 \mathrm{pg} \mathrm{m}^{-3}$. The linear range of PBDEs was from $1.25 \mathrm{pg} \mathrm{m}^{-3}$ to $5000 \mathrm{pg} \mathrm{m}^{-3}$. Limits of detection (LODs) were calculated as the minimum amount of analyte that produces a peak with a signal-to-noise ratio of 3 . The limits of quantification (LOQs) were calculated as the minimum amount of analyte that produces a peak with a signal-to-noise ratio of 10 . The results were shown in Table 3.

Recoveries and precision: Recoveries were performed at two different spiked levels with three parallel experiments for each level. 10 $\mu \mathrm{L}$ and $50 \mu \mathrm{L}$ of $9 \mathrm{OH}$-PBDEs standard mixture were spiked to two extracts of winter atmospheric $\mathrm{PM}_{2.5}$, respectively. Recoveries of $\mathrm{OH}$ PBDEs were $72.1 \%-104.7 \%$ and relative standard deviations were lower than $13.6 \%$. Similarly, $20 \mu \mathrm{L}$ and $100 \mu \mathrm{L}$ of 39 PBDEs standard mixture were spiked to two extracts of winter atmospheric $\mathrm{PM}_{2.5}$, respectively. We obtained the recoveries of PBDEs were between $74.6 \%$ and $104.5 \%$. Relative standard deviations were lower than $13.5 \%$. Two extracts of winter atmospheric $\mathrm{PM}_{2.5}$ were spiked with $20 \mu \mathrm{L}$ and $100 \mu \mathrm{L}$ of BDE209 standard solution, respectively. The recoveries and relative standard deviations for BDE-209 were $76.1 \%-83.0 \%$ and lower than $5.9 \%$ (Table 4).

OH - PBDEs qualitative analysis: The mass spectra of nine $\mathrm{OH}$ PBDEs and BSTFA derivatives were shown in Figure 5.

\section{Application to atmospheric samples study}

We used established method to determine trace amounts of PBDEs and $\mathrm{OH}-\mathrm{PBDEs}$ in $\mathrm{PM}_{2.5}$, which were collected from Baoding, China The information of samples collection was shown in Table 1 . The test results of real atmospheric samples were shown in Table 5. Considering the range of $\mathrm{PM}_{2.5}$, the concentration of winter is obviously higher than that of autumn, which suggests winter heating contribute significantly to $\mathrm{PM}_{2.5}$ concentration. Six PBDEs and five OH-PBDEs were detected in all the samples. The total concentrations of 40 PBDEs in atmospheric samples ranged from 147.1 to $8663.4 \mathrm{pg} \mathrm{m}^{-3}$, while BDE-209 was the largest contributor to PBDEs, ranged from 137 to $5248 \mathrm{pg} \mathrm{m}^{-3}$.

The results indicated that the concentration level and distribution of PBDEs in the atmosphere were influenced by weather conditions. Meanwhile, it was found that the concentration of BDE-209 in the atmosphere was mainly affected by $\mathrm{PM}_{25}$ concentration. The higher the pollution degree was, the higher the $\mathrm{PM}_{25}$ concentration was and the greater the BDE-209 concentration was. The detection rates of BDE47 , BDE-99, BDE-100 and BDE-209 were relatively higher, while the detection rate of BDE- 100 was $100 \%$. It is probably because the penta$\mathrm{BDE}$ commercial mixtures were widely used in China. The detectable amount of BDE-66, BDE-153 and 5 OH-PBDEs was relatively lower It was found that the total detectable amount of low-brominated OH-PBDEs was higher than high-brominated OH-PBDEs, and it is possiblely related to the content of bromine atoms of PBDEs. The less bromine atoms content of PBDEs' are, the faster their oxidation rates are. There is a certain relationship between the content of $\mathrm{OH}$ PBDEs and weather conditions. The total detectable amount of $\mathrm{OH}-$ PBDEs was relatively lower in clean and sunny weather, while the total detectable amount of OH-PBDEs was relatively higher in heavy haze.

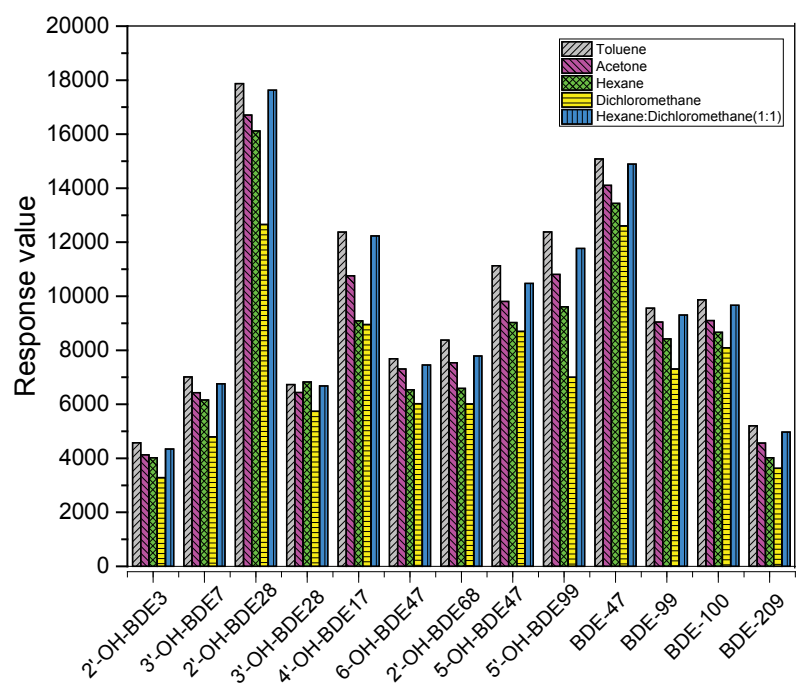

Figure 4: Effect of extraction solvent on extraction efficiency. 
Citation: Liu P, Xu Y, Wang X, Li Z, Jing G (2017) Determination of Nine Hydroxylated Polybrominated Diphenyl Ethers and Forty Polybrominated Diphenyl Ethers in Atmospheric Fine Particles by Precolumn Derivatization-GC-MS/GC. J Environ Anal Toxicol 7: 518. doi: 10.4172/21610525.1000518
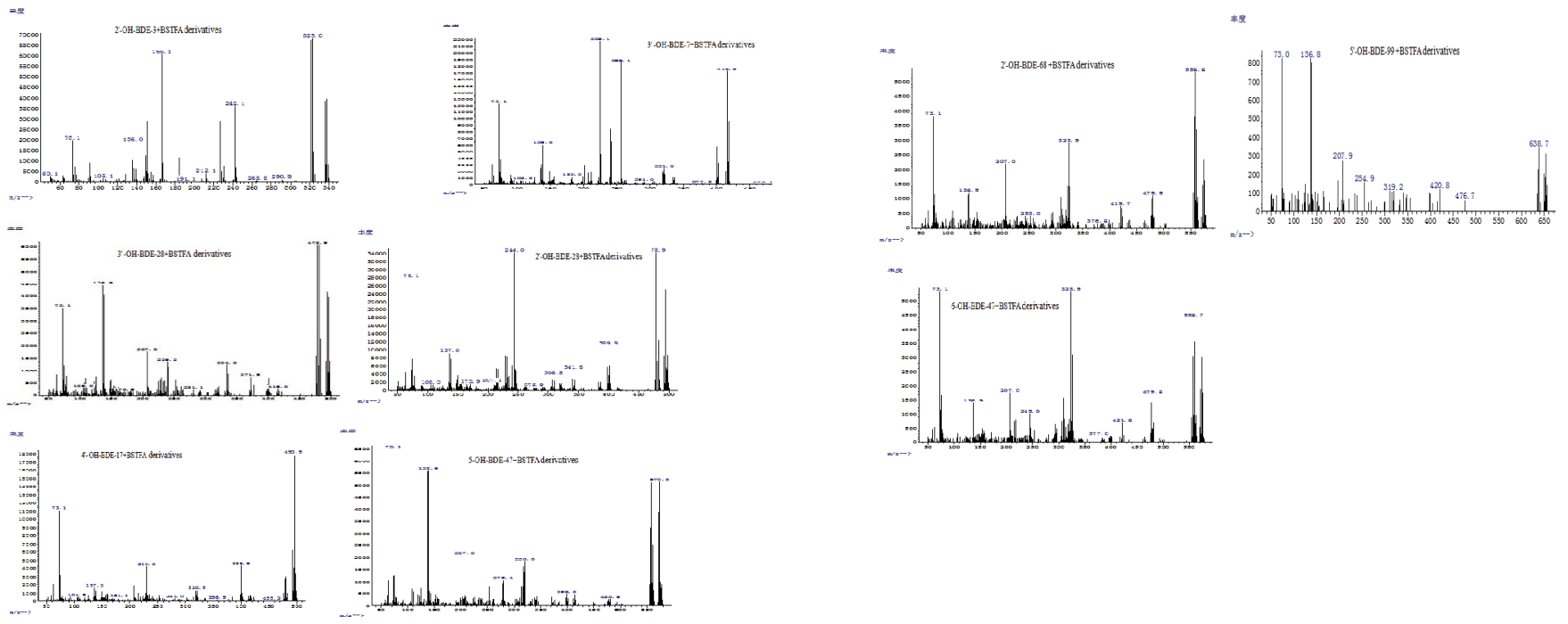

Figure 5: Mass spectrum of derivatives.

\begin{tabular}{|c|c|c|c|c|}
\hline OH-PBDEs/PBDEs & Linear equation & $r^{2}$ & $\begin{array}{c}\text { LOD } \\
\left(\mathrm{ng} \mathrm{m}^{-3} \times 10^{-3}\right)\end{array}$ & $\begin{array}{c}\text { LOQ } \\
\left.\text { (ng m } \text { m }^{-3} \times 10^{-3}\right)\end{array}$ \\
\hline 2'-OH-BDE-3 & $y^{1}=629177 x^{2}+5704.3$ & 0.9942 & 4.95 & 16.48 \\
\hline 3'-OH-BDE-7 & $y=382634 x+10117$ & 0.9994 & 6.06 & 20.19 \\
\hline 2'-OH-BDE-28 & $y=484845 x+21149$ & 0.9955 & 6.25 & 20.82 \\
\hline 3'-OH-BDE-28 & $y=208191 x+2762.8$ & 0.9994 & 13.31 & 44.38 \\
\hline 4'-OH-BDE-17 & $y=370617 x+688.63$ & 0.9979 & 15.20 & 50.68 \\
\hline 5-OH-BDE-47 & $y=340213 x+16888$ & 0.9955 & 8.05 & 26.85 \\
\hline 6-OH-BDE-47 & $y=238751 x+4113.3$ & 0.9959 & 12.08 & 40.27 \\
\hline 2'-OH-BDE-68 & $y=195558 x+6964.9$ & 0.9972 & 6.22 & 20.72 \\
\hline 5'-OH-BDE-99 & $y=103934 x+2267.5$ & 0.9946 & 24.33 & 81.09 \\
\hline BDE-1 & $y=49372 x+39.943$ & 0.9991 & 4.93 & 16.45 \\
\hline BDE-2 & $y=37219 x+31.632$ & 0.9990 & 6.94 & 23.15 \\
\hline BDE-3 & $y=25864 x+17.083$ & 0.9987 & 7.98 & 26.59 \\
\hline BDE-10 & $y=691123 x+46.784$ & 0.9997 & 1.28 & 4.28 \\
\hline BDE-7 & $y=526756 x+34.181$ & 0.9989 & 1.83 & 6.09 \\
\hline BDE-11/8 & $y=597150 x+62.428$ & 0.9994 & 2.02 & 6.72 \\
\hline BDE-12/13 & $y=977883 x+92.783$ & 0.9997 & 1.21 & 4.02 \\
\hline BDE-15 & $y=332913 x+48.892$ & 0.9992 & 2.05 & 6.83 \\
\hline BDE-30 & $y=801171 x+92.29$ & 0.9989 & 1.62 & 5.39 \\
\hline BDE-32 & $y=613788 x+61.055$ & 0.9985 & 2.10 & 7.02 \\
\hline BDE-17 & $y=560725 x+64.222$ & 0.9987 & 2.30 & 7.67 \\
\hline BDE-25 & $y=635891 x+70.115$ & 0.9984 & 2.14 & 7.14 \\
\hline BDE-33/28 & $y=1 E+06 x+122.31$ & 0.9990 & 0.75 & 2.51 \\
\hline BDE-35 & $y=661255 x+52.25$ & 0.9985 & 1.97 & 6.58 \\
\hline BDE-37 & $y=734232 x+77.468$ & 0.9987 & 1.86 & 6.22 \\
\hline BDE-75 & $y=757348 x+76.051$ & 0.9986 & 0.50 & 1.67 \\
\hline BDE-49 & $y=640812 x+35.11$ & 0.9986 & 2.00 & 6.68 \\
\hline BDE-71 & $y=660109 x+50.656$ & 0.999 & 2.12 & 7.06 \\
\hline BDE-47 & $y=804617 x+75.571$ & 0.9992 & 0.38 & 1.27 \\
\hline BDE-66 & $y=714850 x+99.093$ & 0.9986 & 1.76 & 5.86 \\
\hline BDE-77 & $y=780365 x+90.701$ & 0.9991 & 1.41 & 4.71 \\
\hline BDE-100 & $y=2 E+06 x+52.542$ & 0.9990 & 0.37 & 1.25 \\
\hline BDE-119 & $y=666848 x+63.729$ & 0.9999 & 0.69 & 2.33 \\
\hline BDE-99 & $y=1 E+06 x+63.563$ & 0.9991 & 0.41 & 1.38 \\
\hline BDE-116 & $y=385855 x+62.261$ & 0.9992 & 2.48 & 8.29 \\
\hline BDE-118 & $y=677724 x+81.653$ & 0.9988 & 1.97 & 6.58 \\
\hline
\end{tabular}


Citation: Liu P, Xu Y, Wang X, Li Z, Jing G (2017) Determination of Nine Hydroxylated Polybrominated Diphenyl Ethers and Forty Polybrominated Diphenyl Ethers in Atmospheric Fine Particles by Precolumn Derivatization-GC-MS/GC. J Environ Anal Toxicol 7: 518. doi: 10.4172/21610525.1000518

Page 7 of 9

\begin{tabular}{|c|c|c|c|}
\hline BDE-85 & $y=562398 x+95.43$ & 0.9988 & 2.85 \\
\hline BDE-126/155 & $y=1 E+06 x+131.59$ & 0.9990 & 1.15 \\
\hline BDE-154 & $y=646329 x+68.595$ & 0.9993 & 1.54 \\
\hline BDE-153 & $y=693962 x+95.181$ & 0.9989 & 2.21 \\
\hline BDE-138/166 & $y=822492 x+134.26$ & 0.9991 & 2.53 \\
\hline BDE-183 & $y=501972 x+67.883$ & 0.9990 & 2.92 \\
\hline BDE-190 & $y=349427 x+62.037$ & 0.9998 & 3.47 \\
\hline BDE-209 & $y=373594 x+83.883$ & 0.9999 & 13 \\
\hline
\end{tabular}

${ }^{1} \mathrm{y}$ represents peak area; ${ }^{2} \mathrm{x}$ reperesents mass concentration, $\mathrm{ng} \mathrm{m}^{-3} \times 10^{-3}$

Table 3: Linear equations, $r^{2}$, LOD and LOQ of OH-PBDEs and PBDEs $(n=3)$.

\begin{tabular}{|c|c|c|c|c|}
\hline \multirow{2}{*}{ OH-PBDEs/PBDEs } & \multicolumn{2}{|c|}{ Level 1} & \multicolumn{2}{|c|}{ Level 2} \\
\hline & Recovery/\% & RSD $/ \%$ & Recovery/\% & RSD/\% \\
\hline 2'-OH-BDE-3 & 89.4 & 8.4 & 85.5 & 1.9 \\
\hline 3'-OH-BDE-7 & 84.0 & 7.0 & 94.0 & 1.6 \\
\hline 2'-OH-BDE-28 & 92.3 & 13.6 & 99.5 & 8.5 \\
\hline 3'-OH-BDE-28 & 86.6 & 10 & 104.7 & 3.3 \\
\hline 4'-OH-BDE-17 & 72.7 & 10.5 & 76.9 & 6.9 \\
\hline 5-OH-BDE-47 & 85.0 & 13.1 & 74.5 & 5.2 \\
\hline 6-OH-BDE-47 & 89.7 & 2.3 & 98.8 & 3.4 \\
\hline 2'-OH-BDE-68 & 72.1 & 7.4 & 97.6 & 6.6 \\
\hline 5'-OH-BDE-99 & 96.9 & 6.8 & 91.8 & 9.7 \\
\hline BDE-10 & 93.2 & 4.8 & 88.1 & 14.0 \\
\hline BDE-7 & 95.2 & 1.5 & 95.2 & 12.8 \\
\hline BDE-11/8 & 103.3 & 8.2 & 97.0 & 10.7 \\
\hline BDE-12/13 & 84.4 & 7.4 & 86.2 & 13.0 \\
\hline BDE-15 & 75.9 & 4.1 & 93.1 & 8.3 \\
\hline BDE-30 & 90.1 & 3.0 & 86.1 & 12.6 \\
\hline BDE-32 & 84.5 & 6.8 & 90.6 & 9.8 \\
\hline BDE-17 & 75.7 & 2.4 & 90.8 & 13.1 \\
\hline BDE-25 & 75.7 & 3.6 & 90.7 & 13.2 \\
\hline BDE-33/28 & 76.5 & 5.3 & 92.3 & 13.2 \\
\hline BDE-35 & 74.6 & 1.9 & 94.9 & 13.5 \\
\hline BDE-37 & 75.5 & 3.6 & 94.9 & 11.2 \\
\hline BDE-75 & 75.1 & 5.1 & 84.2 & 10.6 \\
\hline BDE-49 & 86.1 & 4.9 & 91.0 & 13.4 \\
\hline BDE-71 & 76.9 & 2.6 & 91.2 & 12.9 \\
\hline BDE-47 & 75.2 & 5.2 & 98.2 & 12.1 \\
\hline BDE-66 & 76.1 & 2.2 & 88.5 & 12.0 \\
\hline BDE-77 & 75.3 & 2.2 & 96.5 & 12.8 \\
\hline BDE-100 & 75.9 & 10.3 & 82.8 & 2.0 \\
\hline BDE-119 & 77.3 & 2.9 & 84.9 & 13.2 \\
\hline BDE-99 & 76.5 & 13.5 & 104.5 & 10.7 \\
\hline BDE-116 & 74.6 & 5.4 & 90.5 & 13.0 \\
\hline BDE-118 & 83.3 & 2.6 & 92.1 & 13.5 \\
\hline BDE-85 & 89.1 & 2.3 & 99.8 & 13.0 \\
\hline BDE-126/155 & 79.8 & 0.9 & 100.2 & 10.4 \\
\hline BDE-154 & 89.2 & 5.2 & 95.6 & 10.4 \\
\hline BDE-153 & 74.5 & 3.2 & 94.9 & 13.5 \\
\hline BDE-138/166 & 76.3 & 5.5 & 94.2 & 8.1 \\
\hline BDE-183 & 74.6 & 4.5 & 85.0 & 12.2 \\
\hline BDE-181 & 74.9 & 12.6 & 84.5 & 12.1 \\
\hline BDE-190 & 76.6 & 4.6 & 79.2 & 11.9 \\
\hline BDE-209 & 76.1 & 5.6 & 83 & 5.9 \\
\hline
\end{tabular}

${ }^{1} \mathrm{y}$ represents peak area; ${ }^{2} \mathrm{x}$ reperesents mass concentration, $\mathrm{ng} \mathrm{m}^{-3} \times 10^{-3}$

Table 4: Recoveries and relative standard deviations (RSDs) of OH-PBDEs and PBDEs spiked at two levels $(n=3)$. 
Citation: Liu P, Xu Y, Wang X, Li Z, Jing G (2017) Determination of Nine Hydroxylated Polybrominated Diphenyl Ethers and Forty Polybrominated Diphenyl Ethers in Atmospheric Fine Particles by Precolumn Derivatization-GC-MS/GC. J Environ Anal Toxicol 7: 518. doi: 10.4172/21610525.1000518

Page 8 of 9

\begin{tabular}{|c|c|c|c|c|c|c|c|c|c|c|c|}
\hline No. & $\begin{array}{l}\text { BDE-47 } \\
\left(\mathrm{pg} \mathrm{m}^{-3}\right)\end{array}$ & $\begin{array}{l}\text { BDE-66 } \\
\left(\mathrm{pg} \mathrm{m}^{-3}\right)\end{array}$ & $\begin{array}{l}\text { BDE-99 } \\
\left(\mathrm{pg} \mathrm{m}^{-3}\right)\end{array}$ & $\begin{array}{c}\text { BDE-100 } \\
\left(\mathrm{pg} \mathrm{m}^{-3}\right)\end{array}$ & $\begin{array}{l}\text { BDE-53 } \\
\left(\mathrm{pg} \mathrm{m}^{-3}\right)\end{array}$ & $\begin{array}{c}\text { BDE-209 } \\
\left(\mathrm{pg} \mathrm{m}^{-3}\right)\end{array}$ & $\begin{array}{l}3^{\prime}-\mathrm{OH}- \\
\mathrm{BDE}-7 \\
\left(\mathrm{pg} \mathrm{m}^{-3}\right)\end{array}$ & $\begin{array}{l}\text { 2'-OH- } \\
\text { BDE-28 } \\
\left(\mathrm{pg} \mathrm{m}^{-3}\right)\end{array}$ & $\begin{array}{l}\text { 4'-OH- } \\
\text { BDE-17 } \\
\left(\mathrm{pg}-\mathrm{m}^{-3}\right)\end{array}$ & 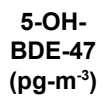 & $\begin{array}{l}5^{\prime}-\mathrm{OH}- \\
\mathrm{BDE}-99 \\
\left(\mathrm{pg} \mathrm{m}^{-3}\right)\end{array}$ \\
\hline 1 & 79.36 & $\mathrm{ND}^{\mathrm{C}}$ & 678.73 & 122.39 & ND & 606 & ND & ND & ND & ND & 87 \\
\hline 2 & 94.55 & ND & 941.07 & 301.75 & 302.05 & 2812 & 27 & ND & 67 & ND & ND \\
\hline 3 & ND & 14.01 & 16.21 & 24.22 & ND & 229 & ND & ND & ND & ND & ND \\
\hline 4 & 9.32 & ND & ND & 141.32 & ND & ND & ND & ND & ND & 34 & ND \\
\hline 5 & ND & ND & 49.11 & 70.07 & ND & 815 & 82 & ND & ND & 29 & ND \\
\hline 6 & 64.10 & ND & 72.26 & 681.21 & ND & 223 & 175 & ND & ND & ND & ND \\
\hline 7 & 10.45 & ND & 36.18 & 43.47 & ND & 346 & ND & ND & ND & ND & ND \\
\hline 8 & 50.03 & 62.21 & ND & 779.30 & ND & 1319 & ND & ND & ND & 30.10 & ND \\
\hline 9 & 19.34 & ND & ND & 227.84 & ND & ND & ND & ND & ND & $\mathrm{ND}$ & ND \\
\hline 10 & ND & ND & 7.26 & 2.82 & ND & 137 & ND & ND & ND & ND & ND \\
\hline 11 & 669.23 & ND & ND & 1408.60 & ND & 828 & ND & 182 & 997 & ND & ND \\
\hline 12 & 32.69 & ND & 13.53 & 342.73 & ND & 519 & ND & 125 & ND & ND & ND \\
\hline 13 & 62.24 & 118.15 & 326.76 & 248.96 & ND & 3182 & ND & 426 & ND & ND & ND \\
\hline 14 & ND & ND & 17.68 & 275.66 & ND & 5248 & ND & 648 & ND & ND & ND \\
\hline 15 & 82.93 & ND & 46.58 & 1576.80 & ND & 3069 & ND & 499 & ND & ND & ND \\
\hline 16 & 193.66 & ND & 103.96 & 4352.77 & ND & 4013 & ND & 584 & ND & ND & ND \\
\hline Total & 1367.9 & 194.37 & 2309.33 & 10599.9 & 302.05 & 23346 & 284 & 2464 & 1064 & 93.10 & 87 \\
\hline
\end{tabular}

Table 5: Detectable amount of PBDEs/OH-PBDEs in16 real samples $(n=3)$.

\section{Conclusions}

The method has been applied to the analysis and separation of trace PBDEs and $\mathrm{OH}-\mathrm{PBDEs}$ in $\mathrm{PM}_{2.5}$, which were collected from Baoding, China. Under the optimum experimental conditions, six PBDEs and five OH-PBDEs were detected in all the samples collected in Baoding, China, and the detection rate of BDE-47, BDE-99, BDE-100 and BDE209 were relatively higher. The results confirmed that the method is simple, convenient, highly sensitive, easy to operate and suitable for the analysis of PBDEs and trace OH-PBDEs in $\mathrm{PM}_{2.5}$.

\section{Acknowledgements}

The authors thank the financial support from the National Natural Science Foundation of China (21377033, NSFC) and the Education Department of Hebei Province (ZD20131046).

\section{References}

1. Usenko CY, Hopkins DC, Trumble SJ, Bruce ED (2012) Hydroxylated PBDEs induce developmental arrest in zebrafish. Toxicology and Applied Pharmacology 262: 43-51.

2. Montaño M, Gutleb AC, Murk AJ (2013) Persistent toxic burdens of halogenated phenolic compounds in humans and wildlife. Environmental Science \& Technology 47: 6071-6081.

3. Tehrani R, Van Aken B (2014) Hydroxylated polychlorinated biphenyls in the environment: sources, fate, and toxicities. Environmental Science and Pollution Research 21: 6334-6345

4. O'Driscoll K, Robinson J, Chiang WS, Chen YY, Kao RC, et al. (2016) The environmental fate of polybrominated diphenyl ethers (PBDEs) in western Taiwan and coastal waters: evaluation with a fugacity-based model. Environmental Science and Pollution Research 23: 13222-13234.

5. Shi Y, Ji Y, Sun H, Hui F, Hu J, et al. (2015) Nanoscale characterization of PM2.5 airborne pollutants reveals high adhesiveness and aggregation capability of soot particles. Scientific Reports, p: 5.

6. Choi JK, Heo JB, Ban SJ, Yi SM, Zoh KD (2013) Source apportionment of
PM 2.5 at the coastal area in Korea. Science of the Total Environment 447: $370-380$.

7. Hu ME, Jing-Hong ZH, Chun-Feng DU, Liang HA, Ya-Feng GU (2014) Therma Desorption-Gas Chromatography or Gas Chromatography-Mass Spectrometry for Analysis of Semi-Volatile Compounds on Atmospheric Particulate Matters. Chinese Journal of Analytical Chemistry 42: 931-936.

8. Niu H, Hu W, Zhang D, Wu Z, Guo S, et al. (2016) Variations of fine particle physiochemical properties during a heavy haze episode in the winter of Beijing. Science of the Total Environment 571: 103-109.

9. Liu H, Hu W, Sun $\mathrm{H}$, Shen O, Wang $X$, et al. (2011) In vitro profiling of endocrine disrupting potency of 2, 2', 4, 4'-tetrabromodiphenyl ether (BDE47) and related hydroxylated analogs (HO-PBDEs). Marine Pollution Bulletin 63: 287-296.

10. Sun J, Liu J, Liu Y, Jiang G (2013) Hydroxylated and methoxylated polybrominated diphenyl ethers in mollusks from Chinese coastal areas. Chemosphere 92: 322-328.

11. Meerts IA, Letcher RJ, Hoving S, Marsh G, Bergman A, et al. (2001) In vitro estrogenicity of polybrominated diphenyl ethers, hydroxylated PDBEs, and polybrominated bisphenol A compounds. Environmental Health Perspectives 109: 399.

12. Lu D, Lin Y, Feng C, Wang D, Quu X, et al. (2014) Determination of polybrominated diphenyl ethers and polychlorinated biphenyls in fishery and aquaculture products using sequential solid phase extraction and large volume injection gas chromatography/tandem mass spectrometry. Journal of Chromatography B 945: 75-83.

13. Li WL, Qi H, Ma WL, Liu LY, Zhang Z, et al. (2015) Brominated flame retardants in Chinese air before and after the phase out of polybrominated diphenyl ethers. Atmospheric Environment 117: 156-161.

14. Albero B, Sánchez-Brunete C, García-Valcárcel Al, Pérez RA, Tadeo JL (2015) Ultrasound-assisted extraction of emerging contaminants from environmental samples. Trends in Analytical Chemistry 71: 110-118.

15. Fujii Y, Nishimura E, Kato Y, Harada KH, Koizumi A, et al. (2014) Dietary exposure to phenolic and methoxylated organohalogen contaminants in relation to their concentrations in breast milk and serum in Japan. Environment International 63: 19-25. 
Citation: Liu P, Xu Y, Wang X, Li Z, Jing G (2017) Determination of Nine Hydroxylated Polybrominated Diphenyl Ethers and Forty Polybrominated Diphenyl Ethers in Atmospheric Fine Particles by Precolumn Derivatization-GC-MS/GC. J Environ Anal Toxicol 7: 518. doi: 10.4172/21610525.1000518

Page 9 of 9

16. Athanasiadou M, Cuadra SN, Marsh G, Bergman Å, Jakobsson K (2008) Polybrominated diphenyl ethers (PBDEs) and bioaccumulative hydroxylated PBDE metabolites in young humans from Managua, Nicaragua. Environmental Health Perspectives 116: 400

17. Qiu X, Bigsby RM, Hites RA (2009) Hydroxylated metabolites of polybrominated diphenyl ethers in human blood samples from the United States. Environmental Health Perspectives 117: 93.

18. Wang HS, Chen ZJ, Ho KL, Ge LC, Du J, et al. (2012) Hydroxylated and methoxylated polybrominated diphenyl ethers in blood plasma of humans in Hong Kong. Environment International 47: 66-72.

19. Eguchi A, Nomiyama K, Subramanian A, Parthasarathy $P$, Kesav AB, et al. (2010) Organohalogen and metabolite contaminants in human serum samples from Indian E-waste recycling workers. Interdisciplinary Studies on Environmental Chemistry 4: 167-174.

20. Ren G, Yu Z, Ma S, Zheng K, Wang Y, et al. (2011) Determination of polybrominated diphenyl ethers and their methoxylated and hydroxylated metabolites in human serum from electronic waste dismantling workers. Analytical Methods 3: 408-413.

21. Stapleton HM, Kelly SM, Pei R, Letcher RJ, Gunsch C (2009) Metabolism of polybrominated diphenyl ethers (PBDEs) by human hepatocytes in vitro. Environmental Health Perspectives 117: 197.

22. Berghe MV, Weijs L, Habran S, Das K, Bugli C, et al. (2012) Selective transfer of persistent organic pollutants and their metabolites in grey seals during lactation. Environment International 46: 6-15.

23. Sun J, Liu J, Liu Y, Jiang G (2013) Hydroxylated and methoxylated polybrominated diphenyl ethers in mollusks from Chinese coastal areas. Chemosphere 92: 322-328.

24. Kajiwara N, Kamikawa S, Ramu K, Ueno D, Yamada TK, et al. (2006) Geographical distribution of polybrominated diphenyl ethers (PBDEs) and organochlorines in small cetaceans from Asian waters. Chemosphere 64: 287-295.

25. Li Y, Lin T, Wang F, Ji T, Guo Z (2015) Seasonal variation of polybrominated diphenyl ethers in PM2. 5 aerosols over the East China Sea. Chemosphere 119: $675-81$.

26. Danaher M, O'Keeffe M, Glennon JD (2000) Validation and robustness testing of a HPLC method for the determination of avermectins and moxidectin in animal liver samples using an alumina column clean-up. Analyst 125:1741-1744.

27. Yu B, Zhang R, Liu P, Zhang Y, Zhang Y, et al. (2015) Determination of nine hydroxylated polybrominated diphenyl ethers in water by precolumn derivatization-gas chromatography-mass spectrometry. Journal of Chromatography A 1419: 19-25.

28. Lacorte S, Ikonomou MG (2009) Occurrence and congener specific profiles of polybrominated diphenyl ethers and their hydroxylated and methoxylated derivatives in breast milk from Catalonia. Chemosphere 74: 412-420. 